\title{
Attenuation of Exercise-induced $R$ Wave Increase after Diltiazem in Effort Angina Pectoris
}

\author{
Isao Kubota, M.D., Hide Igarashi, M.D., Kozue Ikeda, M.D., \\ Michiyasu Yamakt, M.D., Kai Tsuiki, M.D., Shoji Yasui, M.D., \\ and Yoshihiko Watanabe, M.D.*
}

\section{SUMMARY}

Body surface mapping was used to study the effects of diltiazem on exercise-induced QRS amplitude changes in 7 patients with stable effort angina pectoris. Body surface areas showing $\mathrm{R}$ or $\mathrm{S}$ amplitude changes $(>0.2 \mathrm{mV})$ after treadmill exercise were calculated. After the administration of $90 \mathrm{mg}$ of diltiazem, the $\mathrm{R}$ increased area was significantly smaller than that without diltiazem $(\mathrm{p}<0.02)$, although the same workload was performed. It was suggested that diltiazem diminished the exercise-induced myocardial ischemia and this improvement of ischemia resulted in the reduction of the $\mathrm{R}$ increased area after exercise.

\section{Additional Indexing Words:}

Exercise-induced QRS amplitude changes Treadmill exercise test Body surface mapping

HERE are conflicting results concerning the efficacy and sensitivity of exercise-induced QRS amplitude changes in the detection of coronary artery disease. ${ }^{1-13)}$ One contributing factor may be the limited number of leads used in these studies. In a previous report, we used a body surface mapping technique (total 87 leads) to investigate differences in exerciseinduced $\mathrm{R}$ wave amplitude changes between normal subjects and patients with angina pectoris. Normal subjects showed a decrease in the sum of $\mathbf{R}$ waves of 9 precordial leads around $V_{5}\left(\sum R\right)$, while patients with angina pectoris demonstrated an increase in $\Sigma \mathrm{R}$ after exercise. ${ }^{13)}$

If exercise-induced QRS amplitude changes relate to myocardial ischemia,

From the First Department of Internal Medicine, Yamagata University School of Medicine, Yamagata.

* Department of Internal Medicine, Fujita-Gakuen University School of Medicine, Toyoake, Aichi.

Address for reprint: Isao Kubota, M.D., First Department of Internal Medicine, Yamagata University School of Medicine, Zao-Iida, Yanagata 990-23, Japan.

Received for publication September 5, 1983.

Manuscript revised January 11, 1984. 
they may be influenced by the pharmacological intervention aimed at reducing myocardial ischemia. In the present study, we have used a body surface mapping technique to investigate the effects of diltiazem, a calcium channel blocking drug, on exercise-induced QRS amplitude changes in patients with stable effort angina pectoris.

\section{Materials and Methods}

\section{Study group}

Seven men with stable effort angina pectoris formed the study group (mean age 57 years, range 41-66 years). None of the patients had electrocardiographic evidence of previous myocardial infarction or intraventricular conduction defects. Patients with valvular dysfunction, cardiomyopathy or congenital heart disease were excluded. Coronary arteriography revealed significant fixed stenoses $\geqq 75 \%$ of at least one major artery in every patient. All patients had $\geqq 0.1 \mathrm{mV}$ of horizontal or downsloping ST depression in at least one of the standard 12-ECG during submaximal treadmill exercise testing before this study.

\section{Treadmill exercise test using body surface mapping}

Graded exercise testing was performed on a treadmill according to the Bruce protocol.14) The lead-CM5 was monitored continuously, and cuff blood pressure measurements were obtained each minute. Resting heart rate and blood pressure were measured with the subject standing. Eightyseven unipolar electrocardiograms distributed over the entire thoracic surface were sampled simultaneously before and $1.5 \mathrm{~min}$ after the exercise using the HPM-5100 system. ${ }^{15)-17)}$ A sampling rate of 250 samples/sec was used in this study. Data sampling was done at a resting expiratory level in the supine position. The flat portion of the PQ segment was selected as a zero potential line. The potential differences between pre- and post-exercise voltages of $\mathbf{R}$ wave and $\mathbf{S}$ wave at each lead point were measured. Areas of $\mathrm{R}$-wave-amplitude increase and decrease greater than $0.2 \mathrm{mV}$ were computed, and designated as $\mathrm{R}$ increased area and $\mathrm{R}$ decreased area. Similarly, $\mathrm{S}$ increased area and $\mathrm{S}$ decreased area were computed. We used these areas as the indices of the extent of exercise-induced $R$ and $S$ wave changes. The ST segment was measured at $0.06 \mathrm{sec}$ after the $\mathrm{J}$ point, and the area where ST was depressed more than $0.1 \mathrm{mV}$ was calculated (ST depression area). In the present study, the circumference of the chest was normalized at $80 \mathrm{~cm}$ in all subjects. 


\section{Drug protocol}

Exercise tests were performed on two occasions separated by 7 days using the same workload. All cardiovascular medications except sublingual nitroglycerin were stopped at least 3 days before exercise testing. On the day of exercise testing, the use of nitroglycerin was not permitted before the exercise. Exercise tests were carried out at the same time (3PM). All 7 patients terminated first exercise test because of progressive angina. One week after the first test, each patient received a single dose of $90 \mathrm{mg}$ of diltiazem, 3 hours before the exercise test. The second test was conducted using the same workload as in the first test.

\section{Statistical analysis}

Paired t-tests were used to evaluate the effects of diltiazem. The correlation between $\mathrm{R}$ increased area and ST depression area was assessed using

Table I. Systolic Blood Pressure, Heart Rate, Pressure-rate Product, QRS Changed Area and ST Depression Area Before Diltiazem (C) and After Diltiazem (D) Administration

\begin{tabular}{|c|c|c|c|c|c|c|c|c|c|c|c|c|}
\hline \multirow{2}{*}{\multicolumn{2}{|c|}{ Case }} & \multicolumn{2}{|c|}{$\begin{array}{c}\mathrm{SBP} \\
(\mathrm{mmHg})\end{array}$} & \multicolumn{2}{|c|}{$\begin{array}{c}\text { HR } \\
\text { (beats/min) }\end{array}$} & \multicolumn{2}{|c|}{$\begin{array}{l}\text { PRP }\left(\times 10^{2} .\right. \\
\text { beats } \cdot \operatorname{mmHg} / \\
\text { min })\end{array}$} & \multirow{2}{*}{ 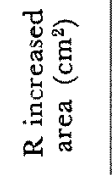 } & \multirow{2}{*}{ 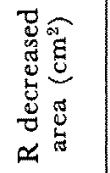 } & \multirow{2}{*}{ 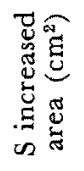 } & \multirow{2}{*}{ 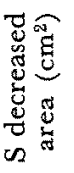 } & \multirow{2}{*}{ 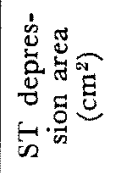 } \\
\hline & & rest & end & rest & end & rest & end & & & & & \\
\hline \multirow[t]{2}{*}{1} & C & 112 & 146 & 69 & 107 & 77 & 156 & 403 & 183 & 466 & 2 & 535 \\
\hline & D & 98 & 146 & 60 & 102 & 59 & 149 & 0 & 136 & 69 & 0 & 343 \\
\hline \multirow[t]{2}{*}{2} & C & 146 & 180 & 80 & 136 & 117 & 245 & 360 & 187 & 404 & 1 & 554 \\
\hline & D & 142 & 186 & 81 & 114 & 115 & 212 & 0 & 116 & 611 & 0 & 304 \\
\hline \multirow[t]{2}{*}{3} & C & 138 & 156 & 84 & 105 & 116 & 164 & 221 & 19 & 386 & 0 & 278 \\
\hline & D & 130 & 160 & 97 & 124 & 126 & 198 & 0 & 0 & 222 & 0 & 121 \\
\hline \multirow[t]{2}{*}{4} & C & 160 & 178 & 66 & 100 & 106 & 178 & 0 & 22 & 215 & 0 & 626 \\
\hline & D & 148 & 178 & 53 & 84 & 78 & 150 & 0 & 1 & 336 & 0 & 54 \\
\hline \multirow[t]{2}{*}{5} & C & 130 & 138 & 63 & 86 & 82 & 119 & 465 & 62 & 1134 & 0 & 291 \\
\hline & $\mathrm{D}$ & 126 & 124 & 48 & 88 & 60 & 109 & 0 & 0 & 0 & 0 & 0 \\
\hline \multirow[t]{2}{*}{6} & $\mathrm{C}$ & 128 & 156 & 67 & 144 & 86 & 225 & 193 & 304 & 404 & 58 & 676 \\
\hline & $\mathrm{D}$ & 106 & 164 & 70 & 135 & 74 & 221 & 40 & 194 & 310 & 9 & 579 \\
\hline \multirow[t]{2}{*}{7} & $\mathrm{C}$ & 116 & 156 & 92 & 140 & 107 & 218 & 21 & 0 & 401 & 0 & 277 \\
\hline & D & 108 & 156 & 88 & 139 & 95 & 217 & 0 & 0 & 183 & 14 & 178 \\
\hline \multirow{4}{*}{$\begin{array}{l}\text { Mean } \\
\pm S D\end{array}$} & C & 133 & 159 & 74 & 117 & 99 & 186 & 238 & 111 & 487 & 9 & 462 \\
\hline & & \pm 17 & \pm 15 & \pm 11 & \pm 23 & \pm 17 & \pm 45 & \pm 183 & \pm 115 & \pm 296 & \pm 22 & \pm 175 \\
\hline & $\mathrm{D}$ & $123 * * *$ & 159 & 71 & 112 & $87 *$ & 179 & $6 * *$ & $64 * *$ & 247 & 3 & $226 * * *$ \\
\hline & & \pm 19 & \pm 20 & \pm 18 & \pm 22 & \pm 26 & \pm 43 & \pm 15 & \pm 83 & \pm 201 & \pm 6 & \pm 199 \\
\hline
\end{tabular}

Abbreviations: $\mathrm{SBP}=$ systolic blood pressure; $\mathrm{HR}=$ heart rate ; $\mathrm{PRP}=$ pressure-rate product ; $\mathrm{C}=$ without diltiazem; $\mathrm{D}=$ with diltiazem.

* $\mathrm{p}<0.05$, ** $\mathrm{p}<0.02, * * * \mathrm{p}<0.01$. 
the least-square method of linear regression analysis. Quantitative data were expressed as mean $\pm \mathrm{SD}$.

\section{RESULTS}

The effects of diltiazem on ST depression area, QRS changed areas and hemodynamic parameters are shown in Table I. At rest, diltiazem significantly reduced the systolic blood pressure (from $133 \pm 17$ to $123 \pm 19 \mathrm{mmHg}$, $\mathrm{p}<0.01$ ) and the pressure-rate product (from $99 \pm 17$ to $87 \pm 26 \times 10^{2}$ beats. $\mathrm{mmHg} / \mathrm{min}, \mathrm{p}<0.05$ ), but it did not change the heart rate significantly (from $74 \pm 11$ to $71 \pm 18$ beats $/ \mathrm{min}$ ). At the end of the exercise, there were no

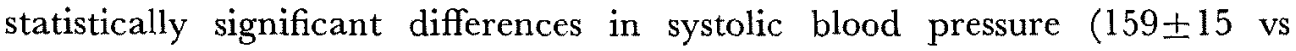
$159 \pm 20 \mathrm{mmHg})$, heart rate $(117 \pm 23$ vs $112 \pm 22$ beats $/ \mathrm{min})$ and pressure-rate product $\left(186 \pm 45\right.$ vs $179 \pm 43 \times 10^{2}$ beats $\left.\cdot \mathrm{mmHg} / \mathrm{min}\right)$ associated with diltiazem administration.

Fig. 1 depicts the effect of diltiazem on ST depression area. With diltiazem, the mean $( \pm \mathrm{SD}) \mathrm{ST}$ depression area was $226( \pm 199) \mathrm{cm}^{2}$, which was significantly smaller $(p<0.01)$ than the value $\left[462( \pm 175) \mathrm{cm}^{2}\right]$ without diltiazem.

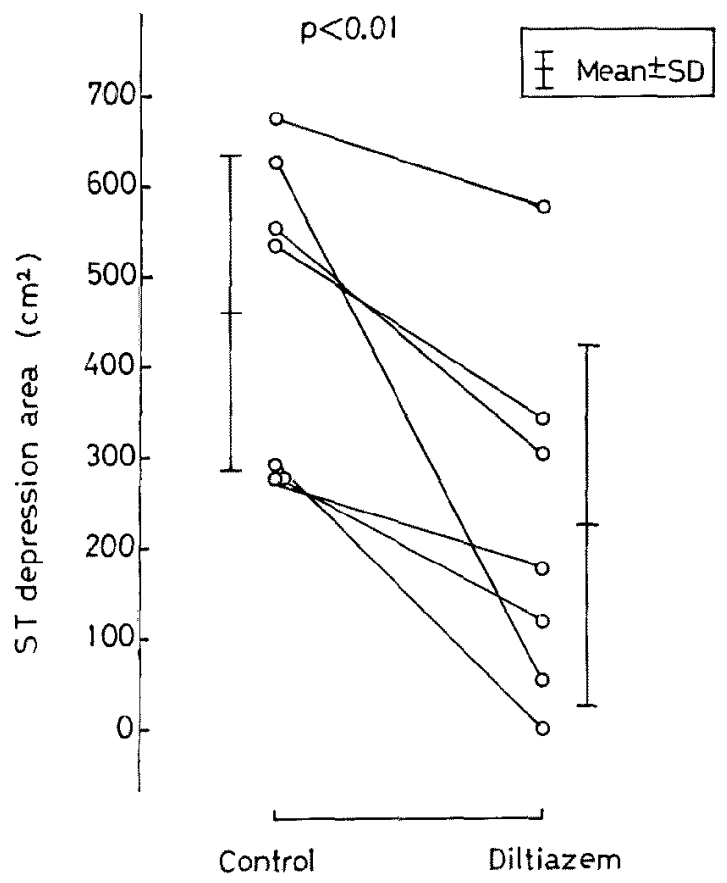

Fig. 1. Effects of diltiazem on the ST depression area. Diltiazem reduced the ST depression area significantly $(\mathrm{p}<0.01)$. 
There were no significant changes in $\mathrm{S}$ increased area and $\mathrm{S}$ decreased area after diltiazem. However, diltiazem significantly reduced the $\mathrm{R}$ increased area and the $\mathrm{R}$ decreased area (Table I). Fig. 2 illustrates the change of $\mathrm{R}$ increased area after diltiazem administration in a representative case (Case 6). The rectangular area represents the torso, with the left side re-
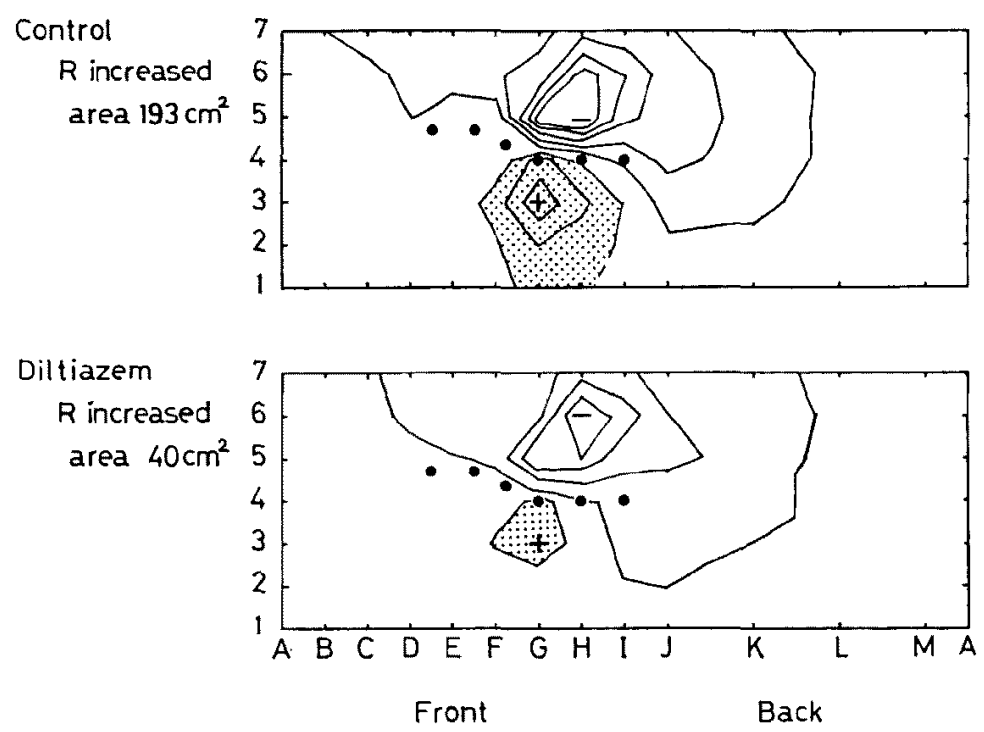

Fig. 2. Changes of $\mathrm{R}$ increased area after diltiazem in a representative case. The shaded region corresponds to an $R$ increased area. Diltiazem diminished the $R$ increased area from $193 \mathrm{~cm}^{2}$ to $40 \mathrm{~cm}^{2}$.

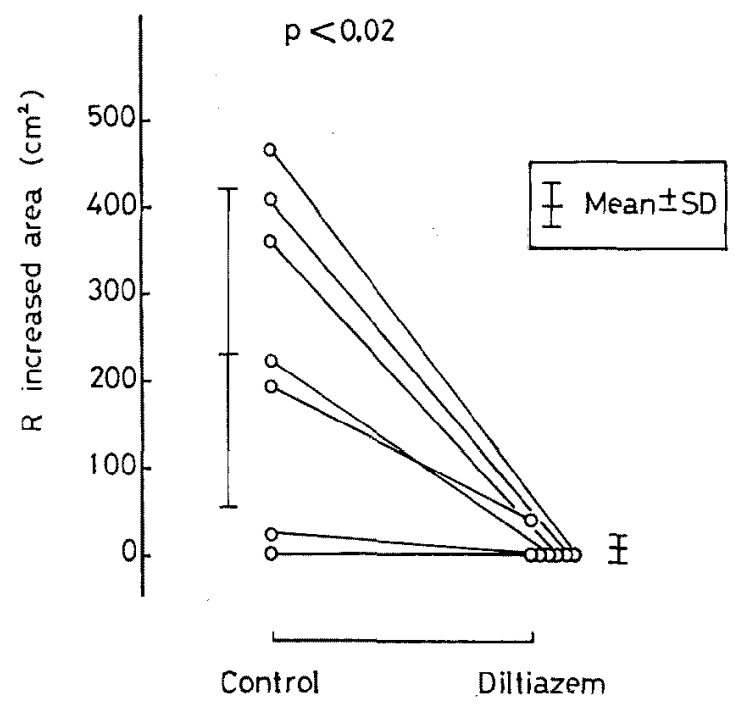

Fig. 3. Effects of diltiazem on the $\mathrm{R}$ increased area. Diltiazem reduced the $R$ increased arca significantly $(p<0.02)$. 


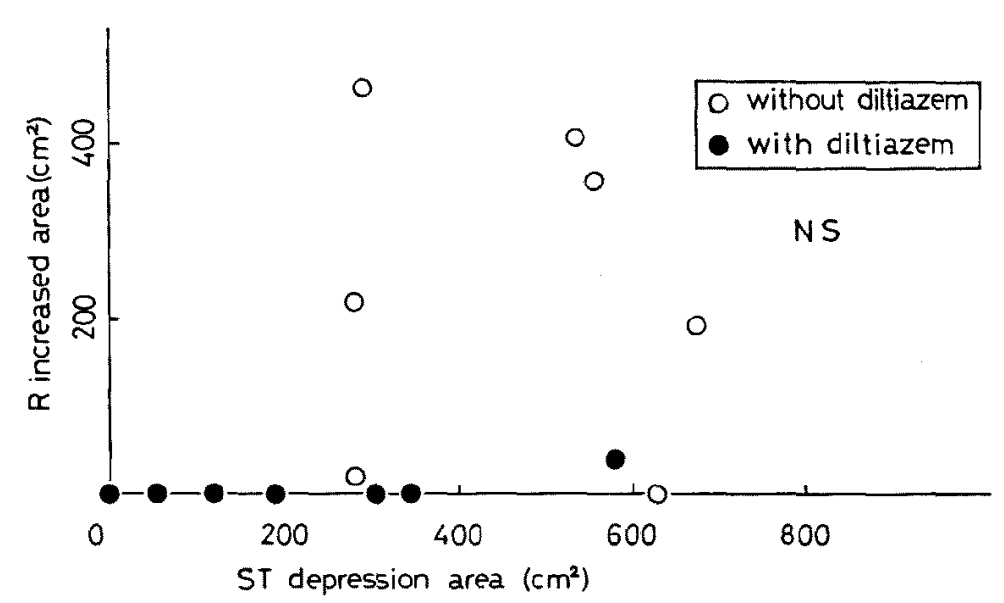

Fig. 4. Correlation between $\mathrm{R}$ increased area and ST depression area. No significant correlation was found.

flecting the anterior chest and the right side the back. Contour lines are drawn at $0.2 \mathrm{mV}$ intervals of $\mathrm{R}$ wave amplitude changes. The shaded region corresponds to the $R$ increased area, where exercise-induced $R$ wave increase is greater than $0.2 \mathrm{mV}$. Locations of the leads $\mathrm{V}_{1}-\mathrm{V}_{6}$ in standard 12-ECG are represented by closed circles. During the first test (upper panel), the $\mathrm{R}$ increased area of $193 \mathrm{~cm}^{2}$ appeared over the left lower anterior chest. The $\mathrm{R}$ increased area decreased to $40 \mathrm{~cm}^{2}$ after diltiazem (lower panel), although the same workload was performed. Fig. 3 shows the effects of diltiazem on the $\mathrm{R}$ increased area in all subjects. Diltiazem reduced the $\mathrm{R}$ increased area significantly (from $238 \pm 183$ to $6 \pm 15 \mathrm{~cm}^{2}, \mathrm{p}<0.02$ ). No correlation was found between the $\mathrm{R}$ increased area and $\mathrm{ST}$ depression area (Fig. 4).

\section{Discussion}

Several recent reports have suggested that an exercise-induced $R$ wave increase can be used to identify patients with coronary artery disease. ${ }^{1-8)}$ In a body surface mapping study, we found that an increase in the sum of $R$ waves of 9 precordial leads $(\Sigma \mathrm{R})$ after exercise indicated the presence of coronary artery disease. ${ }^{13)}$ On the other hand, it has recently been suggested that diltiazem is effective in treating chronic, stable effort angina pectoris. ${ }^{18)-23)}$ Diltiazem increases the exercise time before significant ST depression is observed during multistage exercise testing. ${ }^{18), 19), 21), 22)}$ If exercise-induced QRS amplitude changes are related to both myocardial ischemia and ST depression, they should be influenced by the administration of diltiazem. 
Therefore, we examined the effects of diltiazem on exercise-induced QRS amplitude changes in patients with angina pectoris.

In the present study, we demonstrated that diltiazem reduces the $\mathrm{R}$ increased area as well as ST depression area. These findings may reflect a diltiazem-induced diminution of the exercise-induced myocardial ischemia, which resulted in the reduction of the $\mathrm{R}$ increased area after exercise.

It was reported that the exercise-induced $\mathrm{R}$ wave amplitude changes in normal subjects depend greatly on heart rate. ${ }^{24), 25)}$ However, the reduction of the $\mathrm{R}$ increased area in this study could not be explained by the changes in heart rate, since diltiazem did not elicit the significant changes in heart rate both at rest and at the end of exercise. Therefore, the $\mathrm{R}$ increased area in our study may be related to myocardial ischemia and may be used to detect coronary artery disease.

Some investigators have indicated that the $\mathrm{R}$ wave changes are more sensitive and specific than ST segment changes in the diagnosis of coronary artery disease, ${ }^{1)-4)}$ while others have not confirmed this finding. ${ }^{9)-12)}$ Because patients with significant ST depression after exercise were selected for the present study, a comparative study between the ST depression and the $\mathrm{R}$ wave increase was not feasible. However, 1 patient had no $\mathrm{R}$ increased area (Case 4), and no correlation was found between $R$ increased area and ST depression area (Fig. 4). These results suggest that the mechanism of the $\mathrm{R}$ wave increase after exercise is not identical with that of ST depression, although both are supposed to be related to myocardial ischemia.

The mechanism of the $R$ wave increase could not be elucidated in the present study. In addition, the significance of reduction in the $\mathrm{R}$ decreased area after diltiazem remains to be resolved. Further studies are required to clarify these problems in future.

In conclusion, we demonstrated from this study that a single dose $90 \mathrm{mg}$ of diltiazem could reduce the $\mathrm{R}$ increased area in patients with stable effort angina pectoris. It is suggested that the $\mathrm{R}$ wave amplitude changes in exercise electrocardiograms can be used as a useful index for the detection of myocardial ischemia.

\section{AGKNOWLEDGMENT}

The authors express their gratitude to Professor Kozui Miyazawa for his valuable help in this study,

\section{REFERENCES}

1. Bonoris PE, Greenberg PS, Castellanet MJ, Ellestad MH: Significance of changes in R wave 
amplitude during treadmill stress testing. Angiographic correlation. Am J Cardiol 41: 846, 1978

2. Bonoris PE, Greenberg PS, Christison GW, Castellanet MJ, Ellestad MH: Evaluation of $\mathrm{R}$ wave amplitude changes versus ST-segment depression in stress testing. Circulation 57: 904, 1978

3. Baron DW, Ilsley G, Sheiban T, Poole-Wilson PA: R wave amplitude during exercise. Relation to left ventricular function and coronary artery disease. Br Heart J 44: 512, 1980

4. Christison GW, Bonoris PE, Greenberg PS, Castellanet MJ, Ellestad MH: Predicting coronary artery disease with treadmill stress testing. Changes in R-wave amplitude compared with ST segment depression. J Electrocardiol 12: 179, 1979

5. Ilsley C, Canepa-Anson R, Westgate C, Webb S, Rickards A, Poole-Wilson P: Infuence of $\mathrm{R}$ wave analysis upon diagnostic accuracy of exercise testing in women. Br Heart J 48: 161, 1982

6. Berman JL, Wynne J, Cohn PF: Multiple-lead QRS changes with exercise testing. Diagnostic value and hemodynamic implications. Circulation 61: 53, 1980

7. Berman JA, Wynne J, Mallis G, Cohn PF: Improving diagnostic accuracy of the exercise test by combining R-wave changes with duration of ST segment depression in a simplified index. Am Heart J 105: 60, 1983

8. UhI GS, Andrew J, Hopkirk C: Analysis of exercise-induced $\mathrm{R}$ wave amplitude changes in detection of coronary artery disease in asymptomatic men with left bundle branch block. Am J Cardiol 44: 1247, 1979

9. Battler A, Foelicher V, Slutsky R, Ashburn W: Relationship of QRS amplitude changes during exercise to left ventricular function and volumes and the diagnosis of coronary artery disease Girculation 60: 1004, 1979

10. Wagner $\mathbf{S}$, Cohn $\mathrm{K}$, Selzer A: Unreliability of exercise-induced $\mathrm{R}$ wave changes as indexes of coronary artery disease. Am J Cardiol 44: 1241, 1979

11. Fox KM, England D, Jonathan A, Selwyn A: Inability of exercise-induced $R$ wave changes to predict coronary artcry disease. Am Heart J 49: 674, 1982

12. Deanfield JE, Davies G, Mongiadi F, Savage G, Selwyn AP, Fox KM: Factors influencing $\mathrm{R}$ wave amplitude in patients with ischemic heart disease. Br Heart J 49: 8, 1983

13. Kubota I, Ohyama T, Watanabe Y, Suzuki H, Igarashi H, Harada M, Kaminishi T, Kanaya $\mathrm{T}$, Tsuiki K, Yasui S, Yamaguchi I, Miyazawa $\mathrm{K}$ : Exercise-induced $\mathrm{R}$ wave changes in patients with angina pectoris by body surface mapping and vectorcardiography. Electrocardiology 1: 152, 1981 (in Japanese)

14. Bruce RA, Hornstein ' $\mathrm{IR}$ : Exercise stress testing in evaluating of patients with ischemic heart disease. Prog Cardiovasc Dis 11: 371, 1969

15. Watanabe T, Toyama J, Toyoshima H, Oguri H, Ohta T, Okajima M, Naito Y, Yamada K: A practical microcomputer-based mapping system for body surface, precordium, and epicardium. Comput Biomed Res 14: 341, 1981

16. Kubota I, Saito K, Watanabe Y, Tsuiki K, Yasui S: Treadmill exercise test using body surface mapping. A quantitative diagnostic method for coronary artery disease. Jpn Heart J 22: 871, 1981

17. Kubota I, Watanabe Y, Harada M, Kaminishi T, Tsuiki K, Yasui S: Treadmill stress test using body surfacc mapping in coronary artery disease. The clinical significance of ST depression. Jpn Circulat J 46: 8, 1982

18. Hossack KF, Bruce RA: Improved exercise performance in persons with stable angina pectoris receiving diltiazem. Am J Cardiol 47: 95, 1981

19. Koiwaya Y, Nakamura M, Mitsutake A, Tanaka S, Takeshita A: Increascd exercise tolerance after oral diltiazem, a calcium antagonist, in angina pectoris. Am J Cardiol 47: 95, 1981

20. Kinoshita M, Motomura M, Kusukawa R, Kawakita S: Comparison of hemodynamic effects between $\beta$-blocking agents and a new antianginal agent diltiazem hydrochloride. Jpn 
Circulat J 43: 587, 1979

21. Wagniart P, Ferguson RJ, Ghaitman BR, Achard F, Benacerraf A, Delanguenhagen B, Morin B, Pasternac A, Bourassa MG: Increased excrcise tolerance and reduced electrocardiographic ischemia with diltiazem in patients with stable angina pectoris. Circulation 66: 23, 1982

22. Starling MR, Grawford MH, O'Rourke RA: Diltiazem. Effects on exercise performance in patients with coronary artery disease. Int J Cardiol 1: 229, 1982

23. Kubota I, Watanabe Y, Ohyama T, Igarashi H, Oguma M, Tsuiki K, Yasui S: The beneficial effect of diltiazem on exercisc-induced ST depression, measured by body surface mapping, in stable effort angina pectoris. Clin Ther $5: 49,1982$

24. Wolthuis RA, Froelicher VF, Hopkirk A, Fischer JR, Keiser N: Normal electrocardiographic waveform characteristics during treadmill exercise testing. Circulation 59: 1028, 1979

25. Froelicher VF, Wolthuis R, Fischer J, Uhl G: Variations in normal electrocardiographic response to treadmill testing. Am J Cardiol 47: 1161, 1981 